\title{
Age/Sex/Location: Uncovering the Social Cues in the Development of Online Relationships
}

\author{
MONICA WHITTY, Ph.D., ${ }^{1}$ and JEFF GAVIN, Ph.D. ${ }^{2}$
}

\begin{abstract}
Past research on online relationships has predominantly been concerned with how the quality of online relationships compares with offline relationships. This research has been more concerned with the medium itself than with the meanings that users construct around their interpersonal interactions within this medium. The current paper seeks to redress this imbalance by exploring the ways that available social cues are used to shape the meanings of online relationships. Sixty Internet users, ranging in age from 19-51 years, were interviewed about their online relationships. It was found that ideals that are important in traditional relationships, such as trust, honesty, and commitment are just as important in online relationships; however, the cues that signify these ideals vary.
\end{abstract}

\section{INTRODUCTION}

$\mathbf{R}$ ECENT FIGURES ESTIMATE that approximately 262 million people world-wide access the Internet, ${ }^{1}$ with research showing up to $60 \%$ of newsgroup users having formed personal relationships with someone they have met for the first time online. ${ }^{2}$ Ongoing academic discussions have focused on the similarities and differences between "online" and "traditional" relationships, with opinion divided over the importance of available social cues in the creation and maintenance of online relationships. For example, Slouka ${ }^{3}$ has argued that online relationships are shallow and impersonal. This argument is taken up by several others who contend that the relative lack of social cues on the Internet renders online relationships more hostile and less fulfilling than tra- ditional face-to-face relationships. ${ }^{4,5}$ This argument is supported by Kraut et al. ${ }^{6}$ who found that a high level of Internet use is associated with depression and loneliness. In contrast, others argue that Internet relationships are just as emotionally fulfilling as face-to-face relationships; any lack of social cues can be overcome, and, with time, the reported differences between online and offline relating dissipates. ${ }^{2,7-10}$ This argument is supported by research indicating that greater Internet use is associated with a greater sense of social and psychological well-being. ${ }^{11}$

Parks and Floyd ${ }^{2}$ argue that these two schools of thought represent two versions of Internet relationships: "One version is of relationships lost, while the other is of relationships liberated and found" (p. 81). Over the past 10 years, however, research has failed unequivo-

\footnotetext{
${ }^{1}$ School of Applied Social and Human Sciences, University of Western Sydney, Sydney, Australia.

${ }^{2}$ Department of Psychology, University of Western Sydney, Sydney, Australia.
} 
cally to support one version or the other. With such large numbers of people participating in these relationships, we believe it is futile to operate within this either/or dichotomy, and instead, focus on the meaning of online relationships to those who participate in them.

The current study focuses predominantly on relationships initiated in chat rooms. These interactions can be one-on-one or group communication, are usually between "real," identified people (although identifies are often fabricated or disguised), and occur in real time (i.e., are synchronous). In particular, this research aims to explore the ways that available cues are taken up and used by chat room participants to shape the meanings of their online relationships.

\section{CMR: Cueless, shallow, and hostile}

Relating over the Internet is usually referred to as computer-mediated communication (CMC), focussing attention on the linguistic characteristics of such interactions. Alternatively the term computer-mediated relating (CMR) is used to emphasize a more general concern with " . . all the varied interpersonal dimensions of interactions" ${ }^{\prime 12}$ (p. 8). We will use the terms CMR and online communication to refer to the process of communicating over the Internet, and online relationships to refer to the friendships and romantic relationships that are initiated via such communication.

Some writers emphatically argue that such relationships are shallow and "meaningless" compared to face-to-face relationships, since they lack the full "bandwidth" provided in face-to-face relationships. ${ }^{3}$ Full bandwidth refers to the full gamut of verbal and nonverbal forms of communication. Theorists such as Slouka ${ }^{3}$ argue that electronic communication provides a sense of intimacy without the emotional investment that leads to close and enduring relationships.

This situation is demonstrated in the "boom or bust" phenomenon, in which a rapid process of intimate self-disclosure leads budding relationships to become "quite intense quite quickly." As argued by Cooper and Sportorali ${ }^{12}$ :
Such an accelerated process of relevation may increase the chance that the relationship will feel exhilarating at first, and become quickly eroticized, but then not be able to be sustained because the underlying trust and true knowledge of the other are not there to support it. (p. 12)

Further, theorists who subscribe to "the social presence theory" and/or "the social context cues theory" argue that online relationships are more impersonal and less intimate than faceto-face relationships. The social presence theory ${ }^{13}$ contends that "social presence" is the feeling that one has that other persons are involved in a communication exchange. Since CMR involves less nonverbal cues (such as facial expression, posture, dress, and so forth) and auditory cues in comparison to face-to-face communication, it is said to be extremely low in social presence. According to this theory, as social presence declines communication becomes more impersonal. Hence, CMR is less personal and intimate. Similarly, the social context cues theory ${ }^{14}$ proposes that online and face-to-face communication differ in the amount of social information available. Social content cues, such as nonverbal behaviors and the physical environment are not available online. The absence of social content cues can lead to more uninhibited behavior, such as verbal aggression, blunt disclosure, and nonconforming behavior. This type of behavior, known as "flaming," has been observed across a range of online settings, including business, governmental, educational, and public networks. ${ }^{2,15}$ Such findings lend further support to the argument that online relationships are less intimate and more aggressive than face-to-face relationships.

\section{CMR: Textually rich and emotionally fulfilling}

A strong counter-argument, however, is provided by Lea and Spears, ${ }^{7}$ who point out that anxieties about the "muddying of social distance" and concerns about bandwidth have been with us since the 1890s when the telegraph and telephones first became a means of communication. They propose that although 
first impressions of individuals who meet over the Internet may be very different from those in face-to-face communication (where gender, age, and physical attractiveness are immediately revealed), the lack of face-to-face contact offers more radical opportunities in relationship development. The study of online relationships requires that we rethink traditional theories of attraction and relationship development and maintenance.

While it is acknowledged that online communication lacks many of the physical and nonverbal cues made available in face-to-face communication, many theorists reject the idea that this "lack" represents an insurmountable obstacle to the development of close personal relationships. Instead, it is argued that textbased cues and the augmentation of CMR with other forms of communication render online relationships as intimate and personally fulfilling as any other. ${ }^{2,7}$

Indeed, research shows that it is too simplistic to argue that CMR is altogether devoid of social cues. Text-based communication is capable of providing complex and subtle social and cultural information. For example, Lea and Spears ${ }^{7}$ contend that complex gender information can be transmitted via text, with certain linguistic cues distinguishing men's contributions from women's. That these cues are taken up by participants is indicated by their effects on gender-based behavior. In social online settings, messages from women receive more attention from men, while in work-related online group discussions women's messages receive less attention from both men and women, and threads initiated by women are less likely to receive a response from the group.

Although this gender-related research points to the $\mathrm{Web}$ as a site of negative experiences for women, it is also argued that the Internet can provide a more positive arena for women to express themselves, particularly in relation to sex:

In the anonymity and safety of Net-space, women may feel free to be more directly and explicitly sexual, without fear of potential reallife consequences (e.g., pregnancy, forced sex, or STD's [sic]) or the need to deal with men's more powerful physical presence."12 (p. 11)
Further, others have argued that the view that online relationships are impersonal is flawed since these arguments do not consider that Internet relationships are not necessarily restricted to CMR. For example, Parks and Floyd ${ }^{2}$ reported that their participants extended their online relationships to include the telephone $(35.3 \%)$, snail mail $(28.4 \%)$, or face-to-face communication (33.5\%). Moreover, Walther ${ }^{8-10}$ has argued that many of the differences between online relationships and face-to-face relationships diminish over time. Although restricted bandwidth may limit the rate of information exchange, this problem can be alleviated by allowing longer and/or more frequent communication. Walther argues that although CMR may be more aggressive at first, with time this dissipates. In fact, Walther ${ }^{9}$ has found that groups communicating via computer achieved more positive interpersonal communication on several levels compared to people communicating face to face.

In conclusion, much of this research does not focus on the intent of Internet users. Instead, it is based on the perceived lack of "bandwidth" and social cues provided online, and their relative importance in creating and sustaining "meaningful" relationships. Although ethically questionable, Lamb's ${ }^{16}$ recent research offers an alternative approach to this question. In this highly deceptive study, Lamb studied people in chat rooms by participating himself. In this way he was able to explore the meanings the users ascribed to their online interactions. He adopted several identities, all of which were teenage bisexual males. He described himself as an honors student, who was athletic, sexually active, financially comfortable, and curious. From his experiences he divided the thousand screen names who contacted him into three broad categories: "The Browsers," genuinely curious people who were exploring the medium and expecting to contact real people; "The Cruisers," who were seeking instant sexual gratification through fantasized sexual relations and masturbation; and "The Pornographers," who wanted to gather and trade pornography.

Clearly, Lamb's categories support both sides of the current scholarly debate about on- 
line relationships. On the one hand are those participants for whom the Internet is a potential forum for intimate and personal relationships, on the other are those seeking emotionally disconnected and superficially erotic encounters. However, for us the important point about this research is that it illustrates that it is not bandwidth that differentiates these categories, but rather the intent of the users themselves.

\section{This research}

To summarize, the Internet is a complex social arena that can create and sustain both shallow, aggressive, and superficially erotic encounters, as well as more positive, emotionally engaged, and committed relationships. The question that concerns us here, however, is not the types of relationships available online, but rather an elucidation of the meanings of online relationships to those who engage in them. Similarly, our concern is not to identify what cues are available online, but instead to explore the ways that available cues are taken up and used to shape these meanings. To this end, we chose to interview people about their online interpersonal interactions.

\section{METHOD}

Sixty interviews were carried out as part of an undergraduate subject named "Relationship Studies," at the University of Western Sydney Nepean, located in the outer Western Suburbs of Sydney, Australia. Students were trained in interviewing techniques, and then given an open-ended, semistructured interview schedule. They were each instructed to interview one friend over the age of 17 , who regularly uses the Internet. The students were then required to transcribe the tape-recorded interviews verbatim. These transcripts, together with signed consent forms, were then submitted to Monica Whitty (the subject coordinator) for analysis by both authors.

Participants were asked questions concerning which modes of communication they use on the Internet, including newsgroups, E-mail, and chat rooms. They were further questioned about the types of relationships formed, the conversations they engage in, how honest they are, and how these relationships relate to off line relationships. This paper focuses on the data generated from discussions relating to chat rooms.

\section{Participants}

Of the 60 transcripts submitted and analyzed, 28 interviews were conducted with men and 32 with women. The participant's ages ranged from 17 to 51 years old, with a mean age of 23 .

\section{FINDINGS}

From online chat to offline talk: The development of trust in internet relationships

Our research supports previous findings that relationships beginning on the Internet often extend beyond the Net. ${ }^{2,17}$ Indeed, some of our participants reported face-to-face (FTF) communication with people they met online. Many of these reported encounters involved one or both partners physically travelling great distances for these meetings - a testament to the strength of the online ties that have been created.

We were chatting for probably on and off for 3-4 months. We decided it was time to meet and everything fell in. She was coming up to Sydney [from Melbourne]. She was staying with friends, but she stayed here. . . We got on like a house on fire. It was a semicomfortable situation. It was a wonderful time, but she wanted to be in a relationship... You can't have a relationship on the Internet. A close friendship was on the Internet, but not romantically. (21-year-old male)

Further, there was a striking similarity in the stages of progression from online to offline communication for our participants. The following quotation illustrates the typical sequence of communicative channels followed in these developing relationships.

I've just always wanted to [meet him] since we first started talking to each other, on like the first time I met him we were just talking for hours and 
hours, and we were like "I've got to meet you tomorrow." We started meeting each other all the time in chat rooms, E-mailing each other all the time, and then started calling. We were like "Do you want my phone number?," "I want to meet you." I was like coming to America next year, "Do you want me to meet you?" He said, like "Yeah." [She did go to America and they met.] (21year-old female)

Having progressed through these stages, several of our participants believed that the Internet eventually becomes obsolete to these relationships.

Yes, I met someone on the Net . . It wasn't like I sat down at my computer and told myself I was going to look for a relationship . . . we were in [Internet] contact for a while, spoke to each other for a while, then decided to meet one day. We were friends for a while and eventually it led to a relationship. It went. . . we were together for about two months. I think once you meet then it goes beyond the Internet, so it becomes just like any other relationship... you get to the point where the Internet becomes obsolete. (23-year-old male)

Such comments appear to lend credence to the argument that this broadening of communication points to a blurring of the distinction between on and offline activities for many young people. As Parks and Floyd state ${ }^{2}$ :

... cyberspace is simply another place to meet. Just like people who meet in other locales, those who meet in cyberspace frequently move their relationships into settings beyond the one in which they met originally. They do not appear to draw a sharp boundary between relationships in cyberspace and those in real life. $^{2}$ (p. 94)

However, our research indicates that some of those involved in Internet relationships do indeed make a clear distinction between communication channels, and that the meaning of these distinct channels carries important symbolic significance in relation to the development of the relationship. It appears that allowing someone to know your E-mail, then your phone number, and finally your address, represents increasing levels of trust in the relationship and in one's online partner.
Normally if I have someone's email address it means that I know them a little better, so I might trust them a little more. (19-year-old male)

It [progressing from E-mail to phone] actually made it closer. Because off the Net. . ., like you talk to people through the Net or through the E-mail and then you exchange [phone] numbers, then it's like a big thing, and yeah you have to be game enough and you should be a bit scared. (20year-old female)

Not only does this progressive sequence from chat, to E-mail, to phone, to face to face represent different levels of trust, but the hope that this sequence of events will be followed represents a strong commitment to these online relationships.

Online commitment: More than just a meeting of minds

Parks and Floyd ${ }^{2}$ define commitment as the expectation that the relationship will continue into the future; it involves "a desire to continue the relationship and the belief that it should and must continue" (p. 88). For our participants, commitment to a relationship means not only that it should and must continue, but that this continuation should take increasingly intimate form, with the ultimate aim of FTF encounters. In fact, we found that the expectation that there will at some point be FTF communication forms a part of the conversational background to many of the online relationships formed by both the men and the women in this study.

... I have met heaps of people from the Internet, but I speak to them for a while [on the Net], then speak to them on the phone, and eventually talk to them in person. You have to meet, it doesn't work if you only speak on the Internet, you end up losing interest after awhile. (19-year-old male)

Furthermore, for some of the participants, the realization that a face-to-face meeting was not likely to emerge out of a close and ongoing Internet relationship was a source of disappointment.

Yes, it's heartbreaking to know that someone is so suited to you yet so far away. (19-year-old female) 
I mean, over the Net, when you go on, there's people from other states so you don't know who you're talking to until you get to know them and hook up with them and start liking them, and realize "OK, they're from another state," and that's where the problem comes because one's here and one's there, and long-distance relationships [over the Internet only] tend to work for a little while but not for too long. (20-year-old male)

However, interestingly, on several occasions these greatly anticipated face-to-face encounters did not live up to expectations. Some relationships seem to work better solely on the Internet. Indeed many of the women who had relationships maintained them purely as online relationships, with some relationships continuing as close online relationships even after less than comfortable face-to-face encounters.

\section{It developed through an interesting chat on IRC and a series of about 500 E-mails. The attraction was merely someone who cared and listened. He was very sensitive and caring, and his picture was hot! \{laughs\} ... we exchanged addresses and he sent me presents on Valentines Day and Easter. We would write a two-page E-mail every day, send sounds to each other, and eventually after six months we talked on the phone. Our phone conversation was very weak so we decided to stick to E-mail . . . We met after eight months of exchanging E-mails. He was a great guy, and it would have worked but he lived in E- mail. It was a good experience though and he was ex- actly like his photo. \{18-year-old female\}}

The final comments of this young woman offer great insight into the experience of online relating for many of the young men in our study. These men do indeed "live" in E-mail; that is, they seem to "come alive" in their online communications. Many of the men in our study experience the Internet as a liberating medium; it allows them the freedom to be themselves. Further, this sense of freedom stems in part from the types of social cues and information often considered to be "lacking" in Internet communication.

Truth, lies and anonymity: Revealing the "true" self through white lies

It is often assumed that online communications lack many of the factors emphasized in traditional accounts of relationship develop- ment. ${ }^{7}$ These include, among other things, physical proximity, information about physical appearance, cues about group membership, and information about broader social membership. As Parks and Floyd ${ }^{2}$ ask, are these conditions really necessary for the development of relationships? Our data indicate that, not only are they not necessary, their absence actually encourages and enhances online relations, especially for young men. In fact, our findings support the claim that "less can mean more... it is precisely the gaps in information as much as the information itself that give mediated sex its allure"7 (p. 218).

Not surprisingly, many of our participants commented on an absence of nonverbal cues in their online communications. What was important about this absence, however, was that it impeded their judgement about the honesty of their online partners.

You lose a certain amount of ability to be able to communicate, umm, in terms of nonverbal communication, body language, stuff like that. Tone of voice is also . . absent from it. You also lose the ability to be able to judge people's honesty effectively. (19-year-old male)

A perceived lack of honesty was a consistent theme throughout many of our interviews, with some of our participants mentioning this as one of the negative aspects of CMC. For example,

I guess the only negative side that I could find is that there are people out there that make it a big ego trip. They like to lie about themselves and the things they talk about, and because this is not easily monitored it causes some major problems between people on the Net. (51-year-old female)

This perception of dishonesty is not unwarranted, as several of our participants admitted to lying themselves. However, a marked gender difference emerged in relation to the reasons given and the nature of these lies. Women tended to lie for reasons of safety:

Oh yeah. Some people just think it's open slaughter on young girls on the Net and come meet me at such and such a place and you're like yeah right I don't think so. You just don't give out too much information. You cover yourself. (20-year-old female) 
In contrast, such reasons were rarely mentioned as mitigating reasons for men's lies:

They all think I'm a six foot tall tanned lifesaver. I tell them certain things that are true, but other things are bull ${ }^{* * * *}$. I mean, I can get away with it so why not? What they don't know won't hurt them. I will admit that I am pretty sly when it comes to smooth talking certain ladies on the Net and if it means lying to get to second base then go for it. (22-year-old male)

This young man appears to personify the popular argument that Internet relationships are shallow and "meaningless." 3 However, the bravado exhibited by this participant paints him as the exception rather than the rule. On the whole, the lies of most men did not signify a shallow relationship with others on the Net, but, paradoxically, opened a space for a deeper level of engagement with others. As one 17year-old male participant articulated it, the perceived lack of honesty on the Net "can work both ways." This idea is clearly expressed in the following interview extracts:

You can never be sure that anyone you talk to on the Net is telling the truth so there's very little trust. That can work both ways because you're free to be whatever you like, which means you're not intimidated by what people think. (17-year-old male)

You also lose the ability to be able to judge people's honesty effectively. It's a lot easier to do that in person, um, but there's a certain advantage to it. You lose your inhibitions, your insecurities. You can talk a lot more easily to people. It's a bit of an even cut of pros and cons. (29-year-old male)

Such statements support previous research indicating that computer users report less self-consciousness and awareness of being socially evaluated, which in turn allows intimate selfrevelation while maintaining distance and personal space. ${ }^{18}$ Specifically it supports Turkle's ${ }^{18}$ conclusion that it is a feeling of anonymity that allows for increased risk-taking with revelations.

Many of the male participants believed that by disguising their identity, they could be more emotionally honest and open. As Cooper and Sportolari ${ }^{12}$ (p. 11) argue, "the safety and space available for online interactions on the net allows people a chance to experiment with putting normally inhibited parts of themselves forward." Moreover, Parks and Roberts ${ }^{17}$ compare this phenomenon to Thibaut and Kelley's ${ }^{19}$ "stranger-on-the-train" theory; whereby people feel more comfortable disclosing to someone that they will probably never meet again.

For the young men in our study, this unique sense of safety and space is called forth by the sense of anonymity that the Internet engenders. This sense of anonymity is maintained by the white lies that people tell each other on the Net.

\section{Oh, man, I have lied about $f^{* * *}$ ing everything - my age, my name, what I do, and that type of $s h^{* *}$. I guess I mainly bull **** about the things that would give away who I am. (21-year-old male)}

Ah ... I lied about where I lived because someone I was actually talking [chatting] to lived very close to me and I didn't want her to find out who I was.

(20-year-old)

Lea and Spears ${ }^{7}$ distinguish between two types of anonymity in online communication: anonymity of others to the person and anonymity of the self to others. They refer to the latter type of anonymity as "identifiability." For our participants both types of anonymity shape the space in which they can be themselves; however, it is only in relation to identifiability that these participants actively tell lies. These participants tell white lies to maintain identifiability, and once established this type of anonymity opens up the space for them to be more "truthful" than they would otherwise be face to face.

\section{If you don't want anyone to know who you are, you can basically say and do anything you like. It also seems easier to open up to people because you can't see them, you know what I mean? It's like because they're not in front of you, it doesn't matter how you look or sound because it all reduces down to words. (17-year-old male)}

This quote is interesting also because it supports the claim of Lea and Spears ${ }^{7}$ that "[t]he visual anonymity of the communicators and the lack of co-presence of the communication add to the interaction possibilities, and for some this is the 'magic' of on-line relationships" (p. 202). In fact, a very strong sense of "visual anonymity" runs 
through many of our participants' accounts of the "freedom" opened up by the Net.

There are no limits because people can't see you and you are anonymous. I feel more comfortable speaking about anything on the Net compared to real life. (19-year-old)

\begin{abstract}
. . . because people are just you know, you're not just there sort of to, all you have to do is talk, nobody sees you, so there's no inhibitions in a chat room, everybody's just like, there's messages left, right and center, everyone says whatever they want to say. (19-year-old male)
\end{abstract}

\section{CONCLUSION}

In conclusion, questions about "bandwidth" and the differences between face to face and online communication, although interesting, fail to appreciate fully the shared nature of these practices. The ideals that are important in traditional relationships, such as trust, honesty, and commitment, are equally important online, but the cues that signify these ideals are different. For example, lying does not necessarily signify deception on the part of the liar, but instead can signify a desire to reveal a deeper level of truth about the self. Similarly, phoning an online partner does not necessarily indicate a dissatisfaction with online communications, but instead can signify a greater commitment to the relationship. The ways these cues are taken up and appropriated by online users to construct the meanings of their online relationships highlights the need to investigate, not just the medium itself, but the social practices going on between people within this medium.

\section{REFERENCES}

1. Global Research. (2000, February). Global Internet Statistics (by Language). Retrieved March 4, 2000. Online document: http://www.euromktg.com/globstats/

2. Parks M.R., \& Floyd, K. (1996). Making friends in cyberspace. Journal of Communication, 46:80-97.

3. Slouka, M. (1995). War of the worlds: Cyberspace and the high-tech assault on reality. New York: Basic Books.

4. Berry, W. (1993). Sex, economy, freedom and community. New York: Pantheon.

5. Heim, M. (1992). The erotic ontology of cyberspace.
In: Benedikt, M., (ed.) Cyberspace: First steps. Cambridge, MA: MIT Press, pp. 59-80.

6. Kraut, R., Patterson, M., Lundmark, V., Kiesler, S., Mukopadhyay, T. \& Scherlis, W. (1998). Internet paradox: A social technology that reduced social involvement and psychological well-being? American Psychologist, 53:1017-1031.

7. Lea, M., \& Spears, R. (1995). Love at first byte? Building personal relationships over computer networks. In: Wood, J.T., Duck, S.W., (eds.) Understudied relationships: Off the beaten track. Newbury Park, CA: Sage, pp. 197-233.

8. Walther, J.B. (1992). Interpersonal effects in computermediated interaction: A relational perspective. Communication Research, 19:52-90.

9. Walther, J.B. (1995). Relational aspects of computermediated communication: Experimental observations over time. Organizational Science, 6:186-203.

10. Walther, J.B. (1996). Computer-mediated communication: Impersonal, interpersonal and hyperpersonal interaction. Communication Research, 23:3-43.

11. Bier, A.T., Sherblom, S.A., \& Gallo, M.A. (1996). Ethical issues in a study of Internet use: Uncertainty, responsibility, and the spirit of research relationships. Ethics and Behavior, 6:141-151.

12. Cooper, A., \& Sportolari, L. (1997). Romance in cyberspace: Understanding online attraction. Journal of Sex Education and Therapy 22:7-14.

13. Rice, R.E., \& Love, G. (1997). Electronic emotion: Socioemotional content in a computer mediated communication network. Communication Research, 14:85-108.

14. Sproull, L., \& Kiesler, S. (1986). Reducing social context cues: Electronic mail in organizational communication. Management Science, 32:1492-1512.

15. Lea, M., O'Shea, T., Fung, P., \& Spears, R. (1992). "Flaming" in computer-mediated communication: Observations, explanations, and implications. In: Lea, M., (ed.) Contexts of computer-mediated communication. London: Harvester Wheatshaft, pp. 89-112.

16. Lamb, M. (1998). Cybersex: Research notes on the characteristics of the visitors to online chat rooms. Deviant Behavior, 19:121-135.

17. Parks, M.R., \& Roberts, L.D. (1998). "Making MOOsic": The development of personal relationships online and a comparison to their off-line counterparts. Journal of Social and Personal Relationships, 15:517-537.

18. Turkle, S. (1995). Life on the screen. New York: Simon and Schuster.

19. Thibaut, J.W., \& Kelley, H.H. (1959). The social psychology of groups. New York: Wiley.

Address reprint requests to: Dr. Monica Whitty

School of Applied Social and Human Sciences University of Western Sydney Wessington Campus Locked Bag 1797 DC Penrithow South 1797, Australia E-mail: m.whitty@uws.edu.au 
Copyright of CyberPsychology \& Behavior is the property of Mary Ann Liebert, Inc. and its content may not be copied or emailed to multiple sites or posted to a listserv without the copyright holder's express written permission. However, users may print, download, or email articles for individual use. 
Copyright of CyberPsychology \& Behavior is the property of Mary Ann Liebert, Inc. and its content may not be copied or emailed to multiple sites or posted to a listserv without the copyright holder's express written permission. However, users may print, download, or email articles for individual use. 